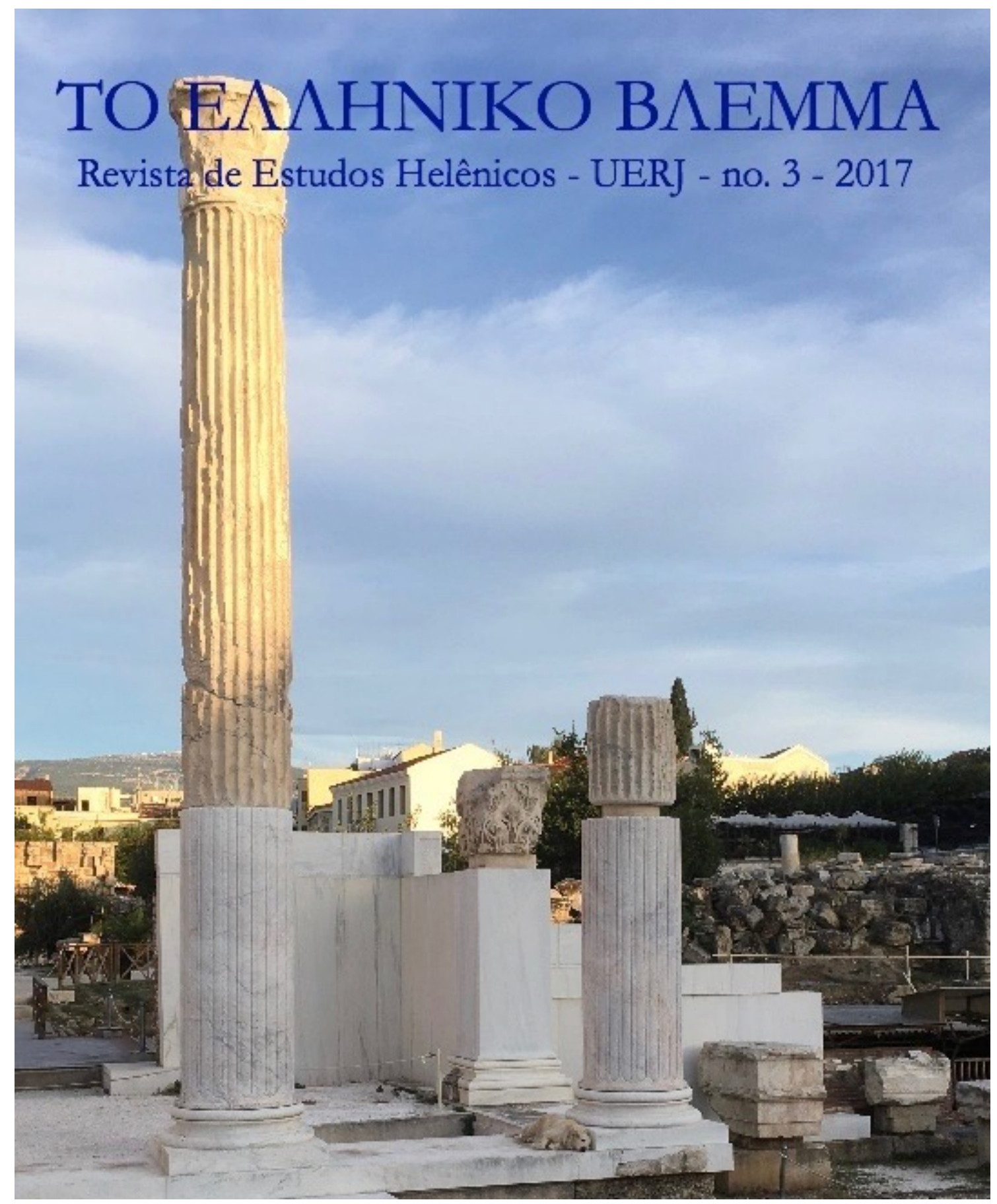




\title{
A Odisseia de Penélope
}

\author{
Elis Crokidakis Castro - UNESA \\ Sandra Verônica Vasque Carvalho de Oliveira - UFRJ
}

\begin{abstract}
RESUMO: Na pós-modernidade, a Odisseia é de Penélope e não de Ulisses. Revisitando o clássico de Homero, através da escritora Margaret Atwood, daremos voz à personagem que, se era antes secundária, agora é a principal do enredo. $\mathrm{O}$ objetivo desse trabalho é, assim, apresentar tal assertiva e as relações existentes entre os textos, mostrando como a antiguidade dialoga com os tempos atuais.
\end{abstract}

Palavras-Chave: Odisseia, Penélope, Pós-modernidade.

\section{The Odyssey is Penelope's}

\begin{abstract}
In postmodernity, Odyssey belongs to Penelope and not to Ulysses. Revisiting Homer's classic, through author Margaret Atwood, we will give voice to the character tha, if it was before secondary, now is the main character of the plot. The objective of this work is to present such an affirmation and shows the existing relations between the texts, showing how an antiquity dialogues with the present times.
\end{abstract}

Key words: Odyssey, Penelope, Postmodernity.

Em famoso e instigante ensaio chamado O que é o contemporâneo, Giorgio Agamben nos convence de que, para entender o hoje, é preciso voltar no tempo, buscar nos primórdios e no arcaico aquilo que nos faça ver a obscuridade do presente. Diz o filósofo que a contemporaneidade "é uma singular relação com o próprio tempo, que adere a este e, ao mesmo tempo, dele toma distâncias" (2009, p. 9). Então,

aqueles que coincidem muito plenamente com a época, que em todos os aspectos a esta aderem perfeitamente, não são 
contemporâneos porque, exatamente por isso não conseguem vê-la, não podem manter fixo o olhar sobre ela.(2009, p.59).

Dessa forma, seguindo o que diz Agamben, para sermos contemporâneos, temos que interpolar o tempo, transformá-lo e colocá-lo em relação com outros tempos para poder ler nele,"de modo inédito a história, de 'citá-la' segundo uma necessidade que não provém de maneira nenhuma do seu arbítrio, mas de uma exigência à qual ele não pode responder"(2009, p.72).

Partindo, então, da nossa posição na contemporaneidade é que leremos a odisseia de Penélope à luz da Odisseia de Ulisses e seus diálogos.

Logo, neste estudo, fruto de uma discussão e investigação quanto à importância da literatura clássica nos dias de hoje, visamos pontuar numa obra atual os ecos que ela possui de uma obra da antiguidade. Assim, partindo da leitura de uma nova odisseia, agora a de Penélope, mostraremos que é inesgotável o diálogo que a literatura contemporânea faz com a literatura clássica, seja pelos temas, pelos personagens, ou mesmo pelas formas, às vezes já evoluídas e outras nem tanto.

Para lançar luz sobre tal diálogo, Italo Calvino, em seu livro Por que ler os clássicos, começa explicando, antes de mais nada, o que são os clássicos. Tal discussão é frutífera e nos remete a toda história da literatura mundial chegando à antiguidade clássica também.

O que são então os clássicos? sugere Calvino que são aqueles

livros que exercem uma influência particular quando se impõem como inesquecíveis e também quando se ocultam nas dobras da memória, mimetizando-se como inconsciente coletivo ou individual. (CALVINO, 1993, p. 10).

Todavia, não se deve confundir e classificar uma obra da antiguidade como se essa fosse necessariamente um clássico. Isto é, não é porque uma obra é antiga que ela é um clássico. Para ser clássico, há de haver, então, toda uma série de elementos, dentre eles, o político, histórico etc., que farão de tal obra uma obra clássica. Sem dúvidas que cada época produz seus clássicos, assim como cada escritor produz seus precursores.

Logo, sem mergulhar profundamente nessas discussões de cunho teórico, no que diz respeito ao ser ou não ser um clássico, voltamo-nos, então, para uma obra que incontestavelmente o é.

Sendo ou não obra de um só autor, Homero, ou de um grupo de autores, a Odisseia ficou na história da literatura mundial como um livro marco da civilização ocidental.

Dessa forma, quanto ao texto de Homero, não se pode esquecer o que as aventuras de Ulisses representaram para os séculos seguintes e para toda a literatura, assim como não se pode "deixar de se perguntar se tais significados estavam implícitos no texto ou se são incrustações, deformações ou dilatações" (CALVINO,1993, p.11), feitas pelo tempo, de toda ideia e ideal ali contidos. 
Assim, a epopeia, que é um formato de texto da antiguidade, apresenta-se com um distanciamento entre o sujeito (narrador) e o objeto narrado. Epos em grego quer dizer recitação, e esta certamente se configurava como um texto que era narrado para um grupo de ouvintes. Não é à toa que em nosso texto analisado percebemos que cada viajante que chegava à casa de Penélope, para falar-lhe de Ulisses, contava, narrava a história que tinha ouvido. Dessa forma, podemos observar as mais variadas versões do mito e escolher a que nos for interessante. Lembramos que o mito era uma narrativa oral sujeita às transformações de cada narrador, por isso suas variantes.

O narrador, assim, põe-se na epopeia em posição de confronto em relação ao que vê e conta o acontecimento passado. Logo, a posição do narrador segue determinado ponto de observação para registrar, mostrar, apontar, apresentar, como bem afirma Emil Staiger (1975).

Possui a epopeia clássica algumas características que serão copiadas ao logo do tempo. A) inalterabilidade da narrativa, o narrador está pouco sujeito aos estados de ânimo, como acontece na lírica, B) a narrativa pretérita e extensa,C) a grandiloquência que são os episódios espetaculares, batalhas sangrentas, exaltação dos heróis sobrehumanos em luta contra a fortuna, D) o desenrolar progressivo dos fatos e E) a autonomia das partes, daí podermos ler cada episódio separadamente, o que é muito comum na contemporaneidade. Reflexo disso é que temos episódios que são mais famosos e conhecidos do que outros.

Esta é a forma da epopeia de Homero, a odisseia de Ulisses, mas e a odisseia contemporânea de Penélope? Podemos dizer que quanto à forma esta será completamente diferente, pois Margaret Atwood constrói em seu texto uma odisseia, mas não uma epopeia.

O tema é conhecido e tem por referência a epopeia, mas a voz que conta não é de outro narrador, mas da própria Penélope e, vez por outra, do Coro, que era formado pelas escravas da personagem principal.

Após sua morte, Penélope vem contar a sua versão de alguns episódios e mostrar, com mesmas e diferentes bases da história original, o que aconteceu.

A autora lembra que, por ser o mito algo local, em cada parte se tinha uma versão diferente e, para que ela pudesse pegar dados da família de Penélope, teve que recorrer a materiais distintos da odisseia de Homero.

Desde o início já muda o foco, muda o olhar e a maneira de observar.

O relato em primeira pessoa sugere uma espécie de diário, de confissão, e confissão nem sempre positiva sobre as pessoas e os fatos.

Inicia, dizendo que já está morta e agora, sim, seria possivel falar, pois em vida certas horas tinha que calar, que fingir que não via e aceitar o que lhe era mandado. Ora, se configura aí o relato de séculos de subjugação das mulheres, da voz que não lhes era dada, isto porque, a mulher na Grécia antiga era menos que um escravo, era propriedade do homem, e eles se casavam pelo dote e não por amor, que foi algo inventado já no romantismo.

Assim, Ulisses casa-se com Penélope, conta esta, por causa do seu dote, pois, na verdade, todos queriam casar com Helena que, na narrativa de Penélope, não é poupada hora alguma, sendo tratada de traidora, de falsa e de tudo que é comum aos sentimentos femininos para com uma rival. Penélope diz que Helena era 
dissimulada, usava seu poder de sedução e a beleza para tudo e diz que foi ela quem destruiu a sua vida, pois, por causa de Helena, Ulisses parte para Tróia.

Nessa releitura do mito, é interessante a mistura dentro da narrativa de questões da vida contemporânea, por exemplo, quando a narradora conta sua história de vida antes de se casar com Ulisses. Ela fala que, no seu tempo, ensinava-se às moças as prendas domésticas e que, hoje, isso não se fazia mais. Em outro trecho, ela fala da cerimônia de casamento e dos presentes. Faz uma crítica às peças que, depois, viram elementos de museus. Portanto, a análise, em sua vida pós morte, é que tudo existente nos museus hoje eram coisas que ficavam guardadas, sem uso, nos antigos castelos. Objetos sem serventia que talvez, por isso, sobreviveram. Também, no capítulo intitulado "A vida doméstica no Hades", notamos a mesma presença da contemporaneidade, que tem relação com a odisseia antiga. A narradora diz que está lá, vendo o mundo aqui embaixo, através de uma médium em transe e que, nessa experiência, uma cliente da médium queria perguntar ao namorado morto se deveria vender seu apartamento. Outros querem falar com tal Marilyn, com tal Adolf; outros, ainda, querem saber os rumos da política e o preço das ações. Desse modo, Penélope faz um comentário muito sarcástico, dizendo que os vivos, era pós era, continuam perturbando os mortos para saber o que fazer aqui na terra, saber o futuro. Na verdade, uma abordagem do Hades nem tão diferente da dada por Homero. No clássico, Ulisses vivo vai ao Hades, também, para saber de seu destino. Ninguém vai até lá vivo como ele o fez, mas lá ele soube o que acontecia em seu reino e lá, a partir das revelações, tece finalmente o seu retorno. Agora, sim, ele quer retornar, talvez antes necessitasse das aventuras.

Quanto às aventuras, Penélope demonstra uma interessante análise. Ela diz que Ulisses jamais abandonará seu espírito aventureiro para ficar ao seu lado. Ele sempre tem de ir. E em sua busca, vai e volta, e aí talvez esteja a grande questão; Penélope, na verdade, ficará sempre à espera da volta de Ulisses, pois este jamais deixará de ser o conquistador, jamais deixará de ir à guerra, de viajar em busca do desconhecido, porque é da própria essência do homem. O que sugere para Calvino que talvez a odisseia seja o mito de todas as viagens, porque ele enxerga várias viagens nessa narrativa. Diz o autor:

talvez para Ulisses/Homero a distinção mentira/verdade não existisse, talvez ele narrasse a mesma experiência ora na linguagem do vivido ora na linguagem do mito, como ainda para nós cada viagem, pequena ou grande, sempre será a odisseia(CALVINO, 1993, p.24).

Ora, para Penélope, no texto de Atwood, não se trata disso, pelo contrário, a narradora zela por uma maior verossimilhança, única realidade dos atos, sem construções míticas. Ela não quer saber do ouvir dizer, de figuras mitológicas, ciclopes, sereias. Ela narra suas artimanhas para sobreviver em meio a adversidade de estar sozinha com seu filho e ter de cuidar do patrimônio do marido. Muito mais uma vivência prática e doméstica do que fantasiosa. Todavia, há uma simetria entre os personagens. Esta diz respeito à estratégia usada por Penélope para enganar os pretendentes, quando ela tece de dia e desfaz à noite, e a 
artimanha usada por Ulisses no cavalo de Troia. Nesse aspecto, os dois são iguais, espertos, inteligentes.

A narradora também fala da relação de Penélope com o pai que a quis abandonar jogando-a no mar, mas que ela foi salva. Daí a dificuldade de desenvolver afeto pelo pai, tudo porque o oráculo havia dito a ele que ela teceria sua mortalha. Diante disso, ela ironiza, dizendo que o pai havia entendido ou interpretado mal o oráculo.

Há, como se vê, uma narradora que faz mais que narrar. Ela constrói o que vai falar, fruto de uma elaboração pessoal, de um sentir e não apenas de um relato do que está vendo. Possui a narrativa de Penélope inúmeros julgamentos de tudo e de todos, juízos de valor que nem sempre cabem a um narrador de epopeia, mas cabem num romance confessional.

Ainda na estrutura textual, percebemos que a construção da personagem se dá de forma diferente da epopeia. Na narrativa de Penélope, parte-se do pressuposto de já ser ela conhecida de forma genérica, cabendo, então, à própria trazer o que fazia parte das entrelinhas, do não explícito na odisseia de Homero. Daí o sumário se apresentar com tópicos que iniciam na infância e vão até a despedida.

Seguindo na trama, Penélope fala também de sua relação com o filho Telêmaco, outro assunto que é muito feminino. A relação mãe e filho é abordada, principalmente, quando o filho, para crescer, precisa se fazer independente da mãe, tendo atitudes livres da influência desta, ainda mais quando o filho é homem, dado o complexo de édipo, que às vezes dura muito.

Assim, a relação de Telêmaco e Penélope fica ruim quando esta tem na sua casa os pretendentes dilapidando o patrimônio de seu marido.

No entanto, iremos nos ater, mais pontualmente, nesta análise, à relação de Penélope com Ulisses.

Já foi dito que ela foi escolhida pelo dote e, por conta da sua relação ruim com o pai, resolveu abandonar a casa dele e ir com Ulisses para Ítaca, um reino sem muito conforto ou riqueza. Pensava ela que lá seria a rainha, e não, mais uma mulher. Contudo, mesmo sendo rainha, não era reconhecida como dona de mando durante o tempo que Ulisses esteve com ela, somente quando ele se foi é que gerenciou e multiplicou a fortuna do marido. É clara, sendo assim, a diferença da narrativa clássica e desta, pois naquela jamais isso seria dito, ou dada essa capacidade de gerenciamento e dominação a uma mulher, mesmo que isto existisse na prática, pois à mulher sempre foi confiada a parte de cuidar da sobrevivência, ou melhor, os encargos domésticos, de cuidar de filhos, da casa, cozinhar etc.

No episódio principal, é preciso que ressaltemos, que nessa narrativa, a qual tem mais forma de romance do que de epopeia, o foco de Penélope não é o retorno, é a espera, que é própria de qualquer mulher. Ela está sempre marcada pelo que se faz enquanto espera os 9 meses de gravidez, o marido voltar, a lavoura crescer, o filho tornar-se adulto e tudo que envolve o estabelecido como função da mulher em qualquer sociedade, que de fato se difere pouco entre oriente e ocidente.

Penélope, primeiro, espera o marido na noite de núpcias. Sua ansiedade ali é construída sobre os ditames dos costumes locais e, como era a noiva teoricamente raptada, a consumação do casamento seria, então, um estupro consentido, teria de ter sangue, como ainda, em muitas sociedades, presenciamos. 
Todavia, Ulisses não foi um bruto, não estava bêbado como a maioria, mas desde aí sua astucia se coloca. Era um homem conversador e, segundo ela, desde a primeira noite conquistou sua confiança.

Podemos dizer que a inteligência de Penélope se sobrepõe à beleza de Helena. E ela, portanto, aprende com Ulisses as artimanhas. Penélope, na nova narrativa, é criada não como o oposto de Ulisses, mas como seu igual como já dissemos. E ela, ao longo de seu percurso dentro do mesmo espaço físico (Itaca) vai criando formas de sobrevivência durante os 20 anos de espera. Além de tecer o manto, Penélope também cria uma espécie de cumplicidade com as escravas, que trazem para ela toda informação de que precisa para sua sobrevivência. Dessa forma, desenvolve pelas escravas uma afeição bastante feminina, trata-as como filhas, o que a faz sofrer quando Ulisses mata todas, por elas terem se envolvido com os pretendentes.

Assim, na narrativa de Atwood, tal cumplicidade entre Penélope e as 12 escravas sugere que Penélope seria a décima terceira, a Suprema Sacerdotisa e que o estupro e enforcamento das 12 seria a destruição do culto matrilinear da lua e o início da defesa de um deus-pai, o patriarcado. Euricleia, também escrava, não fazia parte desse grupo, era fiel a Ulisses e descobre que o forasteiro era Ulisses antes mesmo do confronto final.

As escravas, então, são mortas por Ulisses, acusadas de traição, enquanto Penélope dormia e nada viu, já que Euricleia tinha colocado uma droga em sua bebida e ela perdeu todo o combate.

Há, desse modo, uma ausência de Penélope, quando o combate final começa, e ela só chega depois.

Entretanto, na narrativa de Atwood, há um julgamento de Ulisses, no capítulo 26, por este ato brutal contra as escravas. É um julgamento feito no século XXI e isso é dito, ou seja, à luz de nossas leis. Todavia, o caso não passa desse capítulo onde se colocam outras vozes na narrativa: um juiz qualquer, um advogado de defesa de Ulisses, as escravas e mais um testemunho de Penélope. E assim como surge, tal julgamento não leva a qualquer lugar dentro da estrutura da narrativa. O livro, portanto, termina com uma despedida feita pelas escravas, que viram corujas e vagam pela eternidade.

Desse modo, podemos dizer que, em tal texto, que é uma odisseia e não uma epopeia, a forma é muito diversa, às vezes tradicional romanesca, outras inovadora, com vozes de coro pelo meio. No entanto, o que mais é importante em toda a construção da narrativa são os ares de modernidade, os elementos entre o atual e o antigo, que se confrontam, às vezes, com extremas similitudes, provando que nós mudamos a forma, mas não mudamos a essência, e os mitos clássicos continuam em nosso inconsciente. Daí as mais variadas odisseias modernas que temos como a de James Joyce, Ulisses; a do próprio Ulisses na atualidade, Odisseia:uma continuação moderna, do grego Nikos Kazantzákis. Diante disso, percebe-se a importância que tem a discussão dessa literatura nos dias atuais. 


\section{BIBLIOGRAFIA}

AGAMBEN, Giorgio. O que é o contemporâneo. Chapecó: Argos editora, 2009.

ATWOOD, Margaret. A odisseia de Penélope. São Paulo: Companhia das letras, 2005.

CALVINO, Italo. Por que ler os clássicos? São Paulo: Companhia das letras, 1993.

HOMERO. A odisseia. Rio de Janeiro: Ediouro, 1970.

PAES, José Paulo. Gregos \& baianos. São Paulo: Editora Brasiliense, 1985.

STAIGER, Emil. Conceitos fundamentais da poética. Rio de Janeiro:Tempo Brasileiro, 1975. 